\title{
Neuromuscular Electrical Stimulation and Strength Recovery of Postnatal Diastasis Recti Abdominis Muscles
}

\author{
Dalia M. Kamel, $\mathrm{PhD}^{1,2}$, Amel M. Yousif, $\mathrm{PhD}^{1}$ \\ ${ }^{1}$ Department of Physiotherapy for Obstetrics and Gynecology, Faculty of Physical Therapy, Cairo University, Giza, Egypt; \\ ${ }^{2}$ Department of Physiotherapy, College of Medical \& Health Sciences, Ahlia University, Manama, Bahrain
}

\begin{abstract}
Objective To assess the effect of neuromuscular electrical stimulation (NMES) on the recovery of abdominal muscle strength in postnatal women with diastasis of recti abdominis muscles (DRAM).

Methods Sixty women, 2 months postnatal, participated in this study. They were divided randomly into two equal groups. Group A received NMES in addition to abdominal exercises; group B received only abdominal exercises. The intervention in both groups was for three times per week for 8 weeks. The outcome measures were body mass index (BMI), waist/hip ratio, inter recti distance (IRD), and abdominal muscle strength in terms of peak torque, maximum repetition total work, and average power.

Results Both groups showed highly significant $(\mathrm{p}<0.05)$ improvement in all outcomes. Further, intergroup comparisons showed significant improvement $(\mathrm{p}<0.05)$ in all parameters in favor of group A, except for the BMI.

Conclusion NMES helps reduce DRAM in postnatal women; if combined with abdominal exercises, it can augment the effects.
\end{abstract}

Keywords Abdominal muscles, Diastasis recti, Postnatal care, Electrical stimulation therapy, Exercise

\section{INTRODUCTION}

Diastasis of recti abdominis muscles (DRAM) is defined as a separation of the two rectus abdominis muscles along the linea alba [1]. During pregnancy, the hormonal changes and the uterine growth may stretch the abdominal muscles, mainly the rectus abdominis muscles. As the pregnancy progresses, there is more stretching of the abdominal muscles, loss in their force vector, and perhaps a decrease in contraction strength [2-4]. DRAM is very common during pregnancy with $100 \%$ prevalence at gestational week 35 [5]. It may continue for 6 weeks postnatal, with prevalence of $50 \%$ to $60 \%$, and up to 6 months with less prevalence $(39 \%-45 \%)[5,6]$.

There are many risk factors for developing DRAM, such as the mother's age, multiparity, cesarean section, weight

Received November 14, 2016; Accepted January 23, 2017

Corresponding author: Dalia M. Kamel

Department of Physiotherapy, College of Medical \& Health Sciences, Ahlia University, P.O. Box 10878, Manama, Bahrain. Tel: $+973-3666-3084$, Fax: +973-1729-0083, E-mail: dshewitta@ahlia.edu.bh

ORCID: Dalia M. Kamel (http://orcid.org/0000-0001-8028-6894); Amel M. Yousif (http://orcid.org/0000-0003-4596-1748).

@ This is an open-access article distributed under the terms of the Creative Commons Attribution Non-Commercial License (http://creativecommons.org/ licenses/by-nc/4.0) which permits unrestricted noncommercial use, distribution, and reproduction in any medium, provided the original work is properly cited. Copyright $\odot 2017$ by Korean Academy of Rehabilitation Medicine 
gain, high birth weight, multiple pregnancy, ethnicity, childcare responsibilities $[2,7,8]$, polyhydramnios, and fetal macrosomia [9]. But other studies $[6,10]$ showed no clear risk factors for DRAM, even during 12 months postpartum; so there is still no consensus about the factors that may lead to DRAM.

The abdominal wall is crucial for body posture, trunk and pelvic stability, respiration, trunk movement, and abdominal visceral support [11]. There is increasing focus on how women can regain abdominal strength after childbirth, especially after severe DRAM has altered trunk mechanics, impaired pelvic stability, and changed posture, and has caused vulnerability of the lumbar spine, pelvis injury, and lumbo-pelvic pain and dysfunction $[11,12]$. Lacking scientific knowledge, women are not well informed about abdominal exercise or any other modality that can be used to overcome issue that result from DRAM [6].

Postnatal exercise has many benefits for both mother and baby, including improved cardiovascular fitness, easier weight loss, more energy, better lactation, and infant growth. Furthermore, women who are more active are less likely to be diagnosed with diastasis recti [13]. Strengthening of the abdominal muscles is essential for reducing DRAM and its complications, such as lower back pain [14]. It has been suggested that abdominal muscle exercises should be chosen with care, and that exercises requiring high levels of torque should be avoided [3]. But there is no specific exercise that may or may not help prevent or reduce DRAM during the antenatal and postnatal periods [15]; so development of a validated abdominal exercise program is highly needed.

Neuromuscular electrical stimulation (NMES) is the application of electrical current to elicit a muscle contraction. NMES application has grown significantly in recent years, because it is helpful for strengthening the muscles in orthopedic therapy, mostly being applied to the quadriceps muscle $[16,17]$, and in neurologic rehabilitation $[18,19]$. There are a few studies that investigate the effect of NMES on abdominal muscles. Alon and colleagues [20-22], who were pioneers in this research, found that NMES to the abdominal musculature was well tolerated and strengthened muscles by about $14 \%$ to $22 \%$. But these trials were on normal healthy subjects; as far as we know, there was no trial applied on DRAM. So we chose to investigate the effect of NMES on the recovery of abdominal muscle strength and reduction of DRAM in postnatal women.

\section{MATERIALS AND METHODS}

This study was a randomized control study, approved by the Research Ethical Committee P.T.REC/012/001410, of the Faculty of Physical Therapy, Cairo University, and carried out on 60 postpartum women, at 2 months after giving birth. The subjects were recruited for eligibility from the gynecologic outpatient clinic at Cairo University Hospital (Fig. 1). Their ages ranged from 25 to 35 years, and all gave birth by normal vaginal delivery. Inclusion criteria were diastasis recti more than $2.5 \mathrm{~cm}$ at any point of assessment along the linea alba [7]; body mass index (BMI) less than $30 \mathrm{~kg} / \mathrm{m}^{2}$; waist/hip ratio (WHR) more than 0.85 ; and parity not exceeding four times. Exclusion criteria were previous cesarean section; multiple pregnancies; other abdominal and/or back operations; pregnancy-related complications, such as polyhydramnios, fetal macrosomia, diabetes, or hypertension; abdominal skin diseases; and spinal disorders or lower limb deformities that might hinder the abdominal exercises.

The women were divided randomly into two groups by a simple randomization method (using a shuffled deck of cards). Eligible patients who were recruited on Saturday, Monday, and Wednesday were assigned to the study group A, and those on Sunday, Tuesday, and Thursday were assigned to the control group B. Both groups performed abdominal exercises; group A also received NMES. The groups received their treatment three times per week for 8 weeks. Each woman received a clear demonstration explaining the abdominal exercises; group A also received one about the NMES; and each one signed an informed consent to declare her agreement to take part in this study.

\section{Procedures}

\section{Evaluative procedures}

Evaluations were done before and after the interventions in both groups. The assessor was blind about the group's assignment and was not involved in the treatment application.

(1) Waist and hip circumference measurements: Waist circumference was measured where it was narrowest between the costal margin and the iliac crest at the end of 


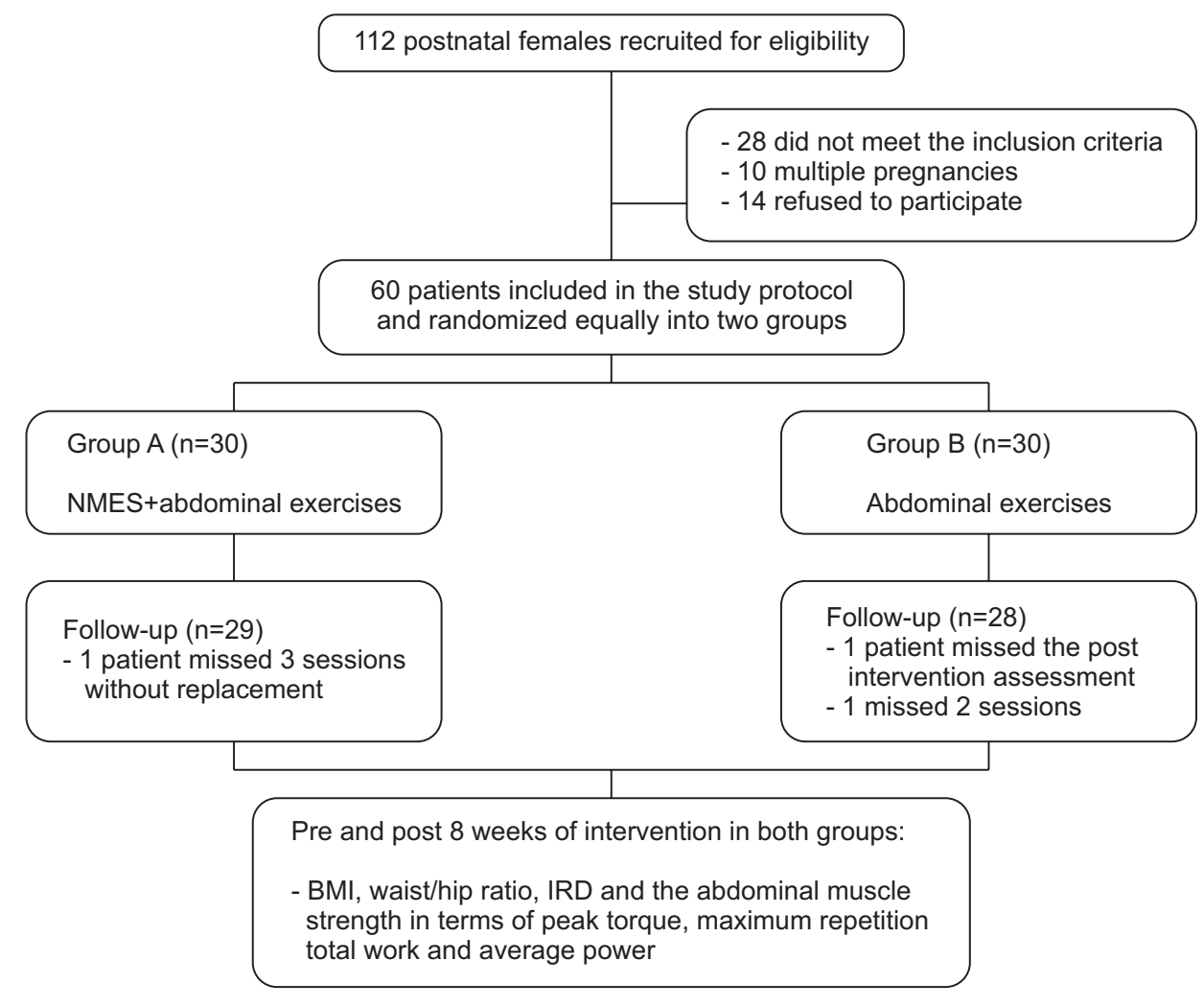

Fig. 1. Flow diagram of patients included in this study by NMES and abdominal exercises versus abdominal exercises only groups. $\mathrm{BMI}$, waist/hip ratio, IRD, and abdominal muscle strength in terms of peak torque, maximum repetition total work, and average power were the outcome measures. NMES, neuromuscular electrical stimulation; BMI, body mass index; IRD, inter recti distance. gentle expiration. The hip circumference was measured where the buttocks were widest as the subject was standing. Then WHR was calculated.

(2) Abdominal muscles strength measurement: Using Isokinetic (Biodex Multi-Joint System Pro, Model 850000; Biodex Medical Systems Inc., New York, NY, USA). An illustrated explanation about the device and how the test was performed was given to each woman, and three training trials were done before the testing began. The test starting position was sitting with $120^{\circ}$ trunk inclination. The lower back was kept in full contact with the seat by applying two adjustable straps on the upper third of the chest; another two straps were crossed over the anterior chest wall to fix the chest from above and below the right and left shoulders. The thighs were fixed to the seat by another two adjustable straps crossing over them, knees were bent $90^{\circ}$, and both feet were supported. The trunk range of motion was from sitting with the trunk at a $120^{\circ}$ angle to the thigh until reaching $45^{\circ}$. The traditional velocity spectrum for flexion and extension in the trunk is $30^{\circ} / \mathrm{s}-150^{\circ} / \mathrm{s}$; the angular velocity for both extension and flexion in this study was set at $60^{\circ} / \mathrm{s}$. The test was repeated three times, and the best repetition was selected for data analysis.
(3) The inter recti distance (IRD): An Ultrasonic transducer (GE Voluson 730 PRO; GE Healthcaere, Waukesha, WI, USA) was used for IRD measurement. The participants assumed a supported and relaxed crook lying position, and the transducer was placed perpendicular to the linea alba, above the umbilicus (midway between the umbilicus and the xiphoid process). Focus and depth were adjusted to visualize the medial aspects of both recti. The hyperechoic connective tissues with the hypoechoic rectus abdominis muscles were identified to measure the IRD at the end of a normal expiration with the automatic ruler to the nearest $0.1 \mathrm{~cm}$ (Fig. 2).

\section{Treatment procedures}

The two groups received their treatments three times per week for 8 weeks.

(1) Neuromuscular electrical stimulation (NMES): A Phyaction E NMES unit (GymnaUniphy N.V., Bilzen, Belgium) was applied only to group A. The NMES was applied first, then followed by the abdominal exercises, in order to take advantage of the improved muscle recruitment [16]. The unit produces an output current of maximum $34 \pm 5 \mathrm{~mA}$ (at $500 \Omega$ load). Its wave parameters are pulse width (100-600 $\mu \mathrm{S})$ and pulse rate (1-500 pulse/s) 

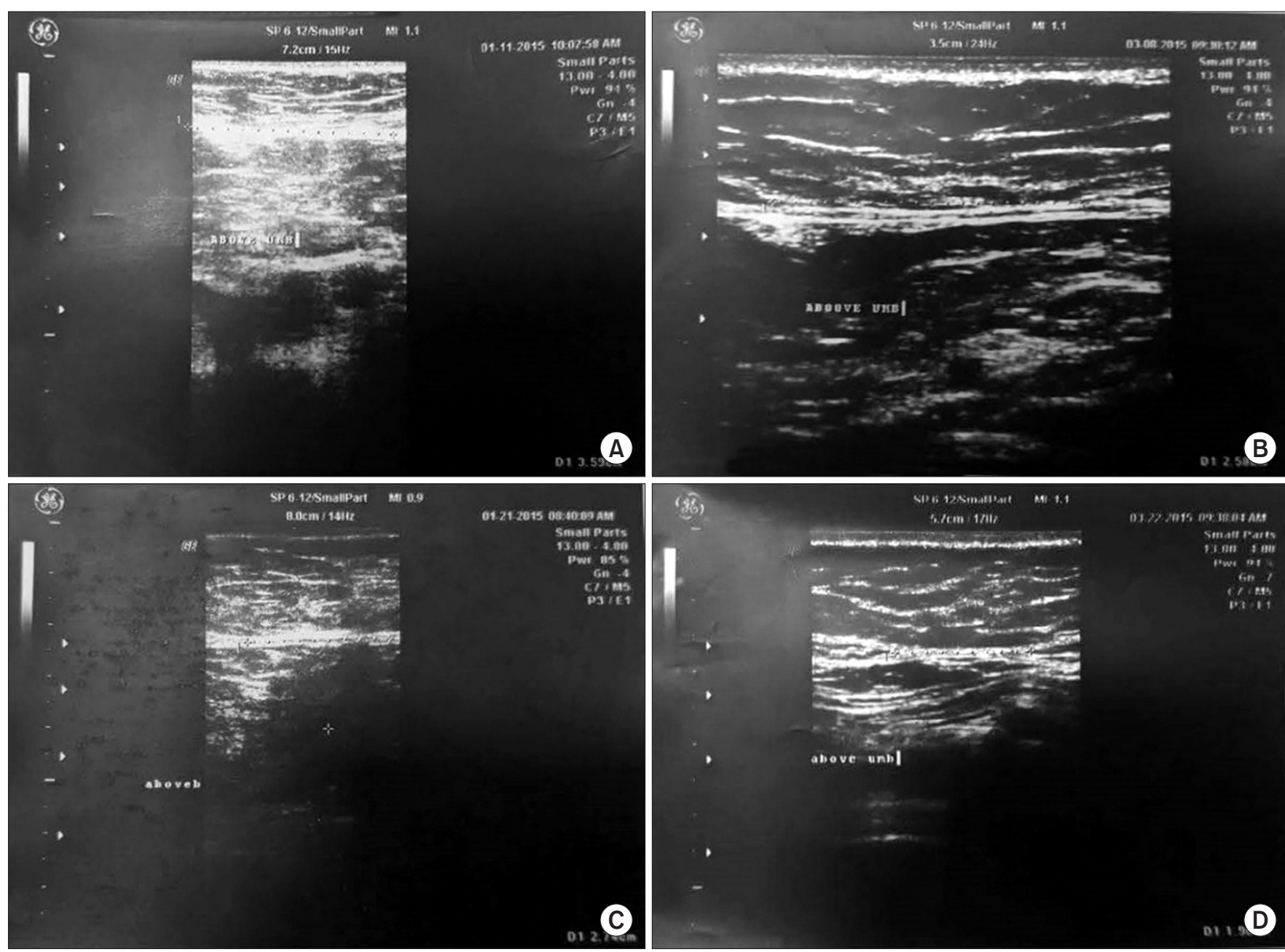

Fig. 2. The inter recti distance (IRD) measurement by ultrasonography in the study group is shown as a dotted line between the two bellies of the rectus abdominis. (A) Pre-IRD measurement showed a distance of $3.59 \mathrm{~cm}$ and (B) post-IRD measurement showed a distance of $2.58 \mathrm{~cm}$. IRD measurement in control group. (C) pre-IRD measurement showed a distance of $2.74 \mathrm{~cm}$ and (D) post-IRD measurement showed a distance of $1.98 \mathrm{~cm}$.

on manual mode.

Before starting the treatment session, each woman was asked to evacuate her bladder for comfort and relaxation. The abdominal area was cleaned with alcohol to remove any debris on the skin and to decrease its resistance to the electrical current. The four large rectangular electrodes used for the stimulation were applied bilaterally for the rectus abdominis. One electrode was placed on the origin of the muscle (at the anterior surface of the pubic crest and in front of the symphysis pubis); the other electrode was placed on the insertion of the same muscle (at the anterior surface of the xiphoid process and the outer surface of the 5, 6, and 7 costal cartilages) (Fig. 3). The electrodes were fixed in their position with straps.
The parameters used for this study were at a frequency 80 pulses/min, with pulse width $0.1-0.5 \mathrm{~ms}$, and as on:off ratio of $5 \mathrm{~s}: 10 \mathrm{~s}$ for the total stimulation time of $30 \mathrm{~min}$ utes. The intensity was increased gradually until a good muscle contraction was seen and felt comfortable. The subjects were instructed to relax their abdominal muscles during NMES applications.

(2) Abdominal exercise program: This program was applied in both groups A and B, illustrations of the exercises were provided, so that the women could repeat the same exercise program on other days as a home routine. All the exercises were performed while the subject tied a scarf around her abdomen. Based on the literature [15], there is no golden standard exercise program for DRAM; so the 

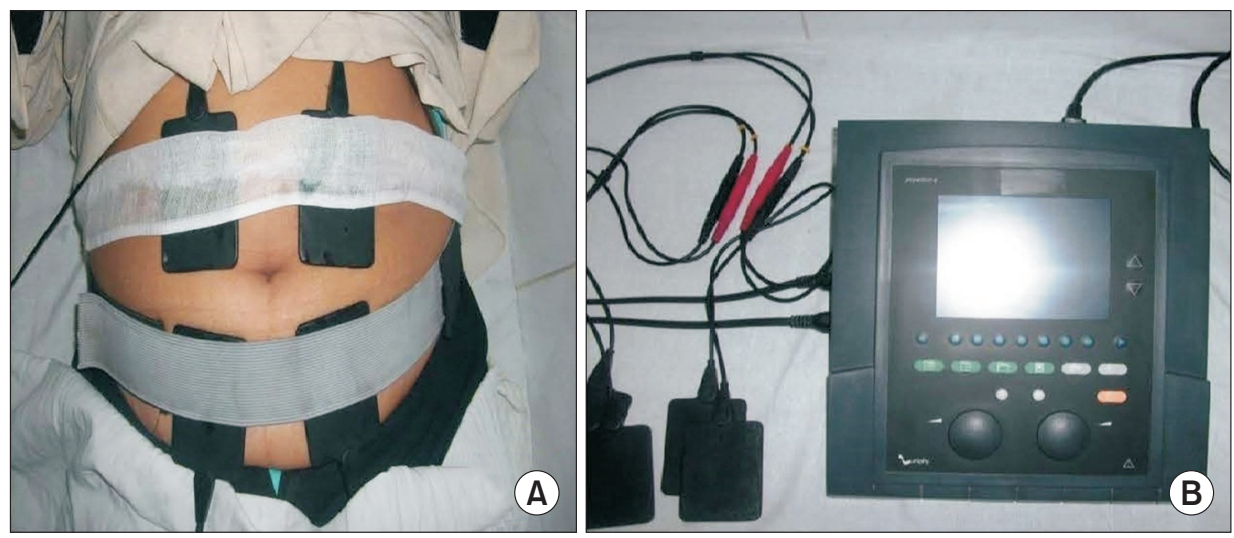

Fig. 3. The neuromuscular electrical stimulation (NMES) application for the study group. (A) Sites of electrode placement for the NMES of the rectus abdominis muscles on each side. The lower electrode is applied on the rectus abdominis muscle's origin; the upper electrode is applied on the muscle insertion. (B) Phyaction E NMES unit.

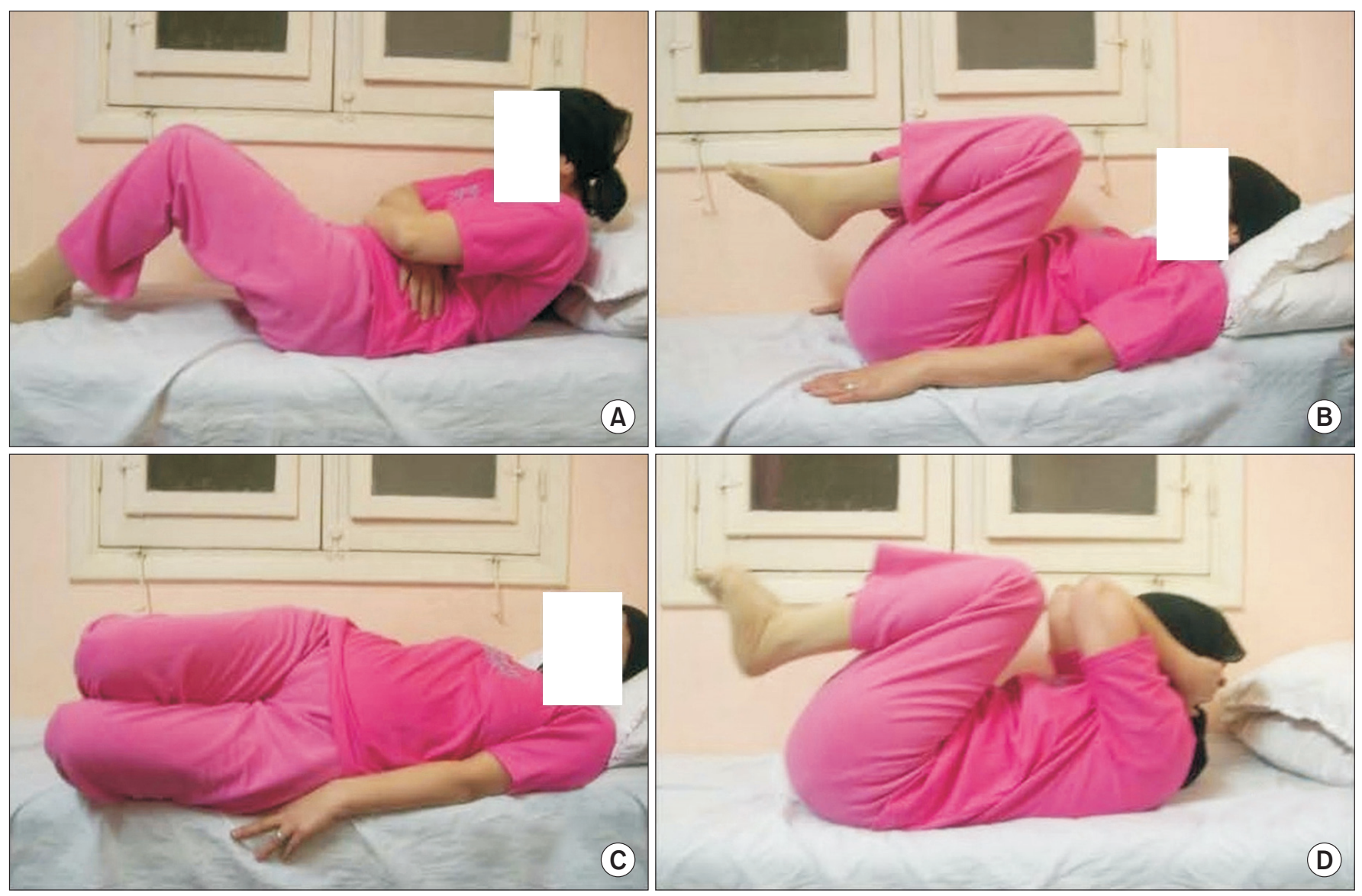

Fig. 4. The abdominal exercises that were performed by both groups. (A) Sit-up exercise, (B) reverse sit-up exercise, (C) reverse trunk twist exercise, and (D) U-seat exercise.

following proposed one included sit ups, reverse sit-ups, reverse trunk twists, and U-seat exercises (Fig. 4). Each exercise was repeated 20 times and was increased by four repetitions each week throughout the interventions. In addition, a respiratory rehabilitation maneuver to involve the abdominal muscles, especially the transverse abdominis, was performed as a diaphragmatic stretching and thoracic blocking maneuver by visual perception of the predominantly abdominal breathing pattern, which was deep inspiration followed by deep expiration accompanied by isometric abdominal muscles contraction [9]. This respiratory rehabilitation maneuver started with a 
set of five times, then was increased by one set each week until the end of the 8-week intervention.

\section{Outcome measures}

Demographic characteristics, WHR, IRD, in addition to the abdominal muscle strength in terms of peak torque, maximum repetition total work, and average power.

\section{Statistical analysis}

The collected data were statistically analyzed by using SPSS ver. 20 (SPSS Inc., Chicago, IL, USA). Descriptive statistics in the form of mean, standard deviation, and percentage were used. A paired t-test was used for comparing within groups, and an independent samples t-test was used to test between groups. In addition, non-parametric test was used for the type of work. A significance level of 0.05 was used throughout all statistical tests; $p$ value $<0.05$ will indicate a significant result, and $p<0.01$ will indicate a highly significant result.

\section{RESULTS}

Both groups involved in this study were homogenous in their demographic characteristics and in the baseline clinical outcome measures (Table 1). The analysis was done on patients who finished all sessions, along with the pre- and post-intervention assessments. Group A ended up with 29 subjects; group B had 28 subjects. In intragroup comparisons, both groups showed highly significant improvement in all the clinical outcomes $(\mathrm{p}<0.05)$ (Table 2).

For the anthropometric measurements of the subjects' BMI, waist circumference, and WHR, group A showed a significant decrease, by $2.46 \mathrm{~kg} / \mathrm{m}^{2}, 6.68$, and $6.66 \%$, and group B also showed a significant decrease, by 2.18 $\mathrm{kg} / \mathrm{m}^{2}, 4.37$, and $3.33 \%$, respectively. For the intergroup comparisons, BMI showed a nonsignificant difference between both groups $(\mathrm{p}=0.223)$, but group A showed a greater reduction in waist circumference and WHR $(\mathrm{p}=$ 0.033 and $p=0.001$, respectively) than group B (Table 3 ).

IRD showed a percentage of reduction in both groups A and B (50\% and $25.88 \%$, respectively). Intragroup comparison showed a significant reduction in both groups (Table 2), but a significantly greater decrease in favor of group A ( $\mathrm{p}=0.0001)$ (Table 3$)$.

The abdominal muscle strength was assessed in terms of peak torque, maximum repetition total work, and average power. Intergroup comparison showed a highly significant $(\mathrm{p}<0.05)$ increase in group A compared to group $B$ in all parameters of muscle strength (Table 3 ). The intragroup comparison showed significant improvement in both groups; improvement in group A was $75.88 \%$,

Table 1. Demographic data and clinical baseline measures of the subjects

\begin{tabular}{|c|c|c|c|}
\hline & Group A $(n=29)$ & Group B $(\mathbf{n}=\mathbf{2 8})$ & p-value \\
\hline Age (yr) & $29.33 \pm 2.98$ & $29.50 \pm 3.00$ & 0.84 \\
\hline Height $(\mathrm{cm})$ & $161.8 \pm 5.13$ & $162.73 \pm 5.06$ & 0.24 \\
\hline Weight (kg) & $73.37 \pm 6.11$ & $74.05 \pm 5.81$ & 0.78 \\
\hline Parity (times) & $2.50 \pm 0.63$ & $2.53 \pm 0.63$ & 0.85 \\
\hline Type of work & & & 0.81 \\
\hline High physical demands & $5(16.7)$ & $6(20)$ & \\
\hline Low physical demands & $14(46.7)$ & $11(36.7)$ & \\
\hline Housewives & $11(36.7)$ & $13(43.3)$ & \\
\hline $\operatorname{BMI}\left(\mathrm{kg} / \mathrm{m}^{2}\right)$ & $28.02 \pm 1.69$ & $27.49 \pm 1.38$ & 0.165 \\
\hline Waist circumference $(\mathrm{cm})$ & $102.80 \pm 5.52$ & $102.56 \pm 5.65$ & 0.867 \\
\hline WHR & $0.90 \pm 0.03$ & $0.90 \pm 0.03$ & 0.477 \\
\hline $\operatorname{IRD}(\mathrm{cm})$ & $2.86 \pm 0.31$ & $2.82 \pm 0.28$ & 0.588 \\
\hline Peak torque $(\mathrm{N} / \mathrm{m})$ & $29.36 \pm 5.87$ & $30.38 \pm 6.22$ & 0.478 \\
\hline maximum repetition total work (J) & $18.95 \pm 4.56$ & $18.07 \pm 5.46$ & 0.479 \\
\hline Average power $(\mathrm{W})$ & $17.48 \pm 4.09$ & $17.93 \pm 4.12$ & 0.493 \\
\hline
\end{tabular}

Values are presented as mean \pm standard deviation or number (\%).

BMI, body mass index; WHR, waist/hip ratio; IRD, inter recti distance. 
Table 2. Outcome measures pre- and post-intervention in both groups

\begin{tabular}{|c|c|c|c|c|c|c|c|c|}
\hline & \multicolumn{4}{|c|}{ Group A $(n=29)$} & \multicolumn{4}{|c|}{ Group B $(\mathbf{n}=\mathbf{2 8})$} \\
\hline & \multirow{2}{*}{ Pre-Tx } & \multirow{2}{*}{ Post-Tx } & \multicolumn{2}{|c|}{$95 \% \mathrm{CI}$} & \multirow{2}{*}{ Pre-Tx } & \multirow{2}{*}{ Post-Tx } & \multicolumn{2}{|c|}{$95 \% \mathrm{CI}$} \\
\hline & & & Lower & Upper & & & Lower & Upper \\
\hline $\mathrm{BMI}\left(\mathrm{kg} / \mathrm{m}^{2}\right)$ & $28.02 \pm 1.69$ & $27.33 \pm 1.68$ & 0.53 & 0.88 & $27.49 \pm 1.38$ & $26.89 \pm 1.44$ & 0.46 & 0.76 \\
\hline Waist circumference $(\mathrm{cm})$ & $102.8 \pm 5.52$ & $95.63 \pm 3.86$ & 6.03 & 8.25 & $102.5 \pm 5.65$ & $98.07 \pm 4.88$ & 3.8 & 5.5 \\
\hline WHR & $0.90 \pm 0.03$ & $0.84 \pm 0.02$ & 0.05 & 0.07 & $0.90 \pm 0.03$ & $0.87 \pm 0.03$ & 0.03 & 0.05 \\
\hline $\operatorname{IRD}(\mathrm{cm})$ & $2.86 \pm 0.31$ & $1.43 \pm 0.38$ & 0.84 & 1.07 & $2.82 \pm 0.28$ & $2.09 \pm 0.35$ & 0.49 & 0.64 \\
\hline Peak torque (N/m) & $29.36 \pm 5.87$ & $51.64 \pm 5.26$ & -24.98 & -19.66 & $30.38 \pm 6.22$ & $46.64 \pm 6.74$ & -18.80 & -13.82 \\
\hline maximum repetition total work $(\mathrm{J})$ & $18.95 \pm 4.56$ & $37.05 \pm 7.92$ & -20.56 & -15.6 & $18.07 \pm 5.46$ & $25.35 \pm 7.90$ & -9.28 & -4.69 \\
\hline Average power (watts) & $17.48 \pm 4.09$ & $30.81 \pm 8.08$ & -15.77 & -10.89 & $17.93 \pm 4.12$ & $23.83 \pm 5.59$ & -6.78 & -3.79 \\
\hline
\end{tabular}

Values are presented as mean \pm standard deviation.

CI, confidence interval; Tx, treatment; BMI, body mass index; WHR, waist/hip ratio; IRD, inter recti distance.

Table 3. Post-intervention outcome measures for both groups

\begin{tabular}{|c|c|c|c|c|c|c|c|}
\hline & \multirow{2}{*}{$\begin{array}{c}\text { Group A } \\
(\mathbf{n}=29)\end{array}$} & \multirow{2}{*}{$\begin{array}{c}\text { Group B } \\
(\mathbf{n}=\mathbf{2 8})\end{array}$} & \multirow{2}{*}{$\begin{array}{c}\text { Mean } \\
\text { difference }\end{array}$} & \multicolumn{2}{|c|}{ 95\% CI } & \multirow{2}{*}{ t-value } & \multirow{2}{*}{ p-value } \\
\hline & & & & Lower & Upper & & \\
\hline $\mathrm{BMI}\left(\mathrm{kg} / \mathrm{m}^{2}\right)$ & $27.33 \pm 1.68$ & $26.89 \pm 1.44$ & 0.502 & -0.313 & 1.316 & 1.23 & 0.223 \\
\hline Waist circumference $(\mathrm{cm})$ & $95.63 \pm 3.86$ & $98.07 \pm 4.88$ & -2.6 & -4.97 & -0.22 & -2.19 & $0.033^{*}$ \\
\hline WHR & $0.84 \pm 0.02$ & $0.87 \pm 0.03$ & -0.03 & -0.04 & -0.01 & -3.40 & $0.001^{*}$ \\
\hline $\operatorname{IRD}(\mathrm{cm})$ & $1.43 \pm 0.38$ & $2.09 \pm 0.35$ & -0.65 & -0.85 & -0.46 & -6.70 & $0.0001^{*}$ \\
\hline Peak torque $(\mathrm{N} / \mathrm{m})$ & $51.64 \pm 5.26$ & $46.64 \pm 6.74$ & 5.22 & 1.95 & 8.50 & 3.20 & $0.002^{*}$ \\
\hline maximum repetition total work (J) & $37.05 \pm 7.92$ & $25.35 \pm 7.90$ & 11.84 & 7.57 & 16.10 & 5.57 & $0.0001^{*}$ \\
\hline Average power (watts) & $30.81 \pm 8.08$ & $23.83 \pm 5.59$ & 7.55 & 3.84 & 11.27 & 4.07 & $0.0001^{*}$ \\
\hline
\end{tabular}

Values are presented as mean \pm standard deviation.

$\mathrm{CI}$, confidence interval; BMI, body mass index; WHR, waist/hip ratio; IRD, inter recti distance.

${ }^{*} \mathrm{p}<0.05$.

95.51\%, and 76.26\%; group B showed 53.52\%, 40.29\%, and $32.9 \%$, respectively (Table 2).

\section{DISCUSSION}

The current study aimed to investigate the effect of the 8 weeks of NEMS on the recovery of abdominal muscles postnatal DRAM. Group A, who received NMES in addition to abdominal exercises, had a reduction of the anthropometric variables and IRD with a significant improvement of the abdominal muscle strength significantly greater than that of group $\mathrm{B}$, who received only abdominal exercises.

The intervention for both groups started after 2 months (8 weeks) postnatal, because the abdominal muscles' ability to stabilize the pelvis against resistance decreases during pregnancy and for at least 8 weeks post birth. Ab- dominal muscle exercises should be chosen with care [3]. Also, the natural resolution and greatest recovery from DRAM occurs between one day and 8 weeks postnatal, at which time recovery plateaus [23]. Furthermore, the intervention protocol in both groups extended for 8 weeks to gain muscle hypertrophy, which cannot be recognized until 8 to 12 weeks after initiating resistance training [24].

Group B, who received abdominal exercises only, showed intragroup significant improvement in all the measured parameters, because abdominal exercises help to strengthen and control abdominal muscles and improve their tone, which reduces the stress on the linea alba [25] and so facilitates the reduction of DRAM.

The current study included a respiratory rehabilitation maneuver in the abdominal exercise program. This maneuver aimed to involve the abdominal muscles, of course, but specifically the transversus abdominis 
muscle, which has strong fascial links with the rectus abdominis muscle and the linea alba [26]; so its activation would draw the rectus abdominis muscles together, reduce DRAM, and allow efficient load transference and torque production [11], as was observed in the results of muscle strength in terms of peak torque, maximum repetition total work, and average power.

For the abdominal exercises, each woman tied a scarf around her abdomen as a form of external support. This type of external support may mimic the fascial tension of the transversus abdominis muscle, would provide compression and support to the abdominal region, and might provide biofeedback for the activation of the transversus abdominis muscle $[27,28]$.

Group A, who received the NMES in addition to abdominal exercises, showed both intragroup and intergroup significant improvement in all the measured parameters. This augmented improvement may be attributed to the higher intensities of muscle overload that lead to the greater strength gains [29] that resulted from combining the NMES and the abdominal muscle exercises.

There is disagreement over whether NMES is more effective than voluntary exercise [30]. One study found that NMES increased strength in healthy muscles when combined with exercise [31], but others found no change in muscle strength [32]. Another found that NMES alone increased muscle strength, but NMES plus exercise training did not [33]. Nevertheless, our result, supported by research on healthy subjects with NMES included in the abdominal training, showed that NMES combined with voluntary exercise could be more effective than exercise alone $[20,22,31,34]$. This shows the need for more research on DRAM.

The benefits of the abdominal exercise program in group A were the same as those gained by group B, but the significant improvement in favor of group A can be attributed mainly to the application of the NMES, which activates the large (type II) nerve fibers at relatively low levels of stimulation [35] and influences the motor cortex excitability [36]. In addition, NMES can recruit deep muscle fibers at lower training intensities, because the nerves stimulated by the NMES are distributed throughout the muscle [16]. Further, muscle contractions induced by electrical stimulation activate a larger proportion of type II muscle fibers than does voluntary exercise at a comparable intensity [37], because typically type II fibers are ac- tivated only during high-intensity voluntary contractions [38].

For the NMES optimal parameters, so far no research has revealed what the most effective parameters combination is [31]; so in our study, the NMES frequency used was set at $80 \mathrm{~Hz}$. This frequency increased muscle strength more than did other frequencies, such as $60 \mathrm{~Hz}$ [39]. Furthermore, during NMES application, the subjects were instructed to relax their abdominal muscles in order to preserve their strength for the exercises, because, according to the literature, muscle contraction superimposed stimulation does not appear to influence traininginduced strength gains [40].

There are some limitations in this study that should be confronted in future research, such as application of NMES on DRAM after a cesarean section and the dose response of the NMES. In addition, the efficacy of the NMES from the commercially portable abdominal stimulation belts should be compared to that of the fixed conventional units. Last, the abdominal exercise program that is currently supposed to be used in the rehabilitation of DRAM needs to be validated.

In conclusion, this study was the first to investigate how NMES affects DRAM. Our results suggest that adding NMES to the DRAM rehabilitation program will be valuable for the recovery of abdominal muscles postnatally.

\section{CONFLICT OF INTEREST}

No potential conflict of interest relevant to this article was reported.

\section{ACKNOWLEDGMENTS}

Thanks to Dr. Mohamed A. Ali, Radiology Department, Cairo University, for the measurement of the IRD for the current study participants.

\section{REFERENCES}

1. Venes D. Taber's cyclopedic medical dictionary. 20th ed. Philadelphia: F. A. Davis; 2005.

2. Spitznagle TM, Leong FC, Van Dillen LR. Prevalence of diastasis recti abdominis in a urogynecological patient population. Int Urogynecol J Pelvic Floor Dysfunct 2007;18:321-8. 
3. Gilleard WL, Brown JM. Structure and function of the abdominal muscles in primigravid subjects during pregnancy and the immediate postbirth period. Phys Ther 1996;76:750-62.

4. Artal R, O'Toole M. Guidelines of the American College of Obstetricians and Gynecologists for exercise during pregnancy and the postpartum period. $\mathrm{Br} \mathrm{J}$ Sports Med 2003;37:6-12; discussion 12.

5. Fernandes da Mota PG, Pascoal AG, Carita AI, Bo K. Prevalence and risk factors of diastasis recti abdominis from late pregnancy to 6 months postpartum, and relationship with lumbo-pelvic pain. Man Ther 2015; 20:200-5.

6. Sperstad JB, Tennfjord MK, Hilde G, Ellström-Engh M, Bo K. Diastasis recti abdominis during pregnancy and 12 months after childbirth: prevalence, risk factors and report of lumbopelvic pain. Br J Sports Med 2016; 50:1092-6.

7. Candido G, Lo T, Janssen PA. Risk factors for diastasis of the recti abdominis. J Assoc Chart Physiother Womens Health 2005;(97):49-54.

8. Turan V, Colluoglu C, Turkyilmaz E, Korucuoglu U. Prevalence of diastasis recti abdominis in the population of young multiparous adults in Turkey. Ginekol Pol 2011;82:817-21.

9. Mesquita LA, Machado AV, Andrade AV. Physiotherapy for reduction of diastasis of the recti abdominis muscles in the postpartum period. Rev Brasil Ginecol Obstet 1999;21:267-72.

10. Rett MT, Braga MD, Bernardes NO, Andrade SC. Prevalence of diastasis of the rectus abdominis muscles immediately postpartum: comparison between primiparae and multiparae. Braz J Phys Ther 2009;13: 275-80.

11. Lee DG, Lee LJ, McLaughlin L. Stability, continence and breathing: the role of fascia following pregnancy and delivery. J Bodyw Mov Ther 2008;12:333-48.

12. Parker MA, Millar AL, Dugan SA. Diastasis rectus abdominis and Lumbo-pelvic pain and dysfunction: are they related? J Womens Health Phys Therap 2009; 33:15-22.

13. Mottola MF. Exercise in the postpartum period: practical applications. Curr Sports Med Rep 2002;1:362-8.

14. Ostgaard HC, Zetherstrom G, Roos-Hansson E, Svanberg B. Reduction of back and posterior pelvic pain in pregnancy. Spine (Phila Pa 1976) 1994;19:894-900.
15. Benjamin DR, van de Water AT, Peiris CL. Effects of exercise on diastasis of the rectus abdominis muscle in the antenatal and postnatal periods: a systematic review. Physiotherapy 2014;100:1-8.

16. Stevens-Lapsley JE, Balter JE, Wolfe P, Eckhoff DG, Kohrt WM. Early neuromuscular electrical stimulation to improve quadriceps muscle strength after total knee arthroplasty: a randomized controlled trial. Phys Ther 2012;92:210-26.

17. Walls RJ, McHugh G, O'Gorman DJ, Moyna NM, O'Byrne JM. Effects of preoperative neuromuscular electrical stimulation on quadriceps strength and functional recovery in total knee arthroplasty. A pilot study. BMC Musculoskelet Disord 2010;11:119.

18. Yun GJ, Chun MH, Park JY, Kim BR. The synergic effects of mirror therapy and neuromuscular electrical stimulation for hand function in stroke patients. Ann Rehabil Med 2011;35:316-21.

19. Guan Y, Wacnik PW, Yang F, Carteret AF, Chung CY, Meyer RA, et al. Spinal cord stimulation-induced analgesia: electrical stimulation of dorsal column and dorsal roots attenuates dorsal horn neuronal excitability in neuropathic rats. Anesthesiology 2010;113:1392405.

20. Alon G, McCombe SA, Koutsantonis S, Stumphauzer LJ, Burgwin KC, Parent MM, et al. Comparison of the effects of electrical stimulation and exercise on abdominal musculature. J Orthop Sports Phys Ther 1987;8:567-73.

21. Alon G, Frederickson R, Gallager L, Rehwoldt CT, Guillen M, Putnam Pement ML, et al. Electrical stimulation of the abdominals: the effects of three versus five weekly treatments. J Clin Electrophysiol 1992;4:511.

22. Alon G, Taylor DJ. Electrically elicited minimal visible titanic contraction and its effect on abdominal muscles strength and endurance. Eur J Phys Med Rehab 1997;7:2-6.

23. Coldron Y, Stokes MJ, Newham DJ, Cook K. Postpartum characteristics of rectus abdominis on ultrasound imaging. Man Ther 2008;13:112-21.

24. Hakkinen K, Newton RU, Gordon SE, McCormick M, Volek JS, Nindl BC, et al. Changes in muscle morphology, electromyographic activity, and force production characteristics during progressive strength training in young and older men. J Gerontol A Biol Sci Med Sci 
1998;53:B415-23.

25. Chiarello CM, Falzone LA, McCaslin KE, Patel MN, Ulery KR. The effect of an exercise program on diastasis recti abdominis in pregnant women. J Womens Health Phys Ther 2005;29:11-6.

26. Lee DG. The pelvic girdle: an approach to the examination and treatment of the lumbopelvic-hip region. 3rd ed. Edinburgh: Churchill Livinstone; 2004.

27. Sheppard S. The role of transversus abdominus in post partum correction of gross divarication recti. Man Ther 1996;1:214-6.

28. Thornton SL, Thornton SJ. Management of gross divarication of the recti abdominis in pregnancy and labour. Physiotheraphy 1993;79:457-8.

29. Steib S, Schoene D, Pfeifer K. Dose-response relationship of resistance training in older adults: a metaanalysis. Med Sci Sports Exerc 2010;42:902-14.

30. McDonough S. Neuromuscular and muscular electrical stimulation. In: Kitchen S, editor. Electrotherapy: evidence-based practice. Edinburgh: Churchill Livingstone; 2008. p. 233-47.

31. Selkowitz DM. Improvement in isometric strength of the quadriceps femoris muscle after training with electrical stimulation. Phys Ther 1985;65:186-96.

32. Paternostro-Sluga T, Fialka C, Alacamliogliu Y, Saradeth T, Fialka-Moser V. Neuromuscular electrical stimulation after anterior cruciate ligament surgery. Clin Orthop Relat Res 1999;(368):166-75.

33. Canning A, Grenier S. Does neuromuscular electrical stimulation improve muscular strength gains of the vastus medialis muscle? Int J Phys Med Rehabil 2014; 2:207.

34. Porcari JP, Miller J, Cornwell K, Foster C, Gibson M, McLean K, et al. The effects of neuromuscular electrical stimulation training on abdominal strength, endurance, and selected anthropometric measures. J Sports Sci Med 2005;4:66-75.

35. Gregory CM, Bickel CS. Recruitment patterns in human skeletal muscle during electrical stimulation. Phys Ther 2005;85:358-64.

36. Tinazzi M, Zarattini S, Valeriani M, Romito S, Farina S, Moretto G, et al. Long-lasting modulation of human motor cortex following prolonged transcutaneous electrical nerve stimulation (TENS) of forearm muscles: evidence of reciprocal inhibition and facilitation. Exp Brain Res 2005;161:457-64.

37. Sinacore DR, Delitto A, King DS, Rose SJ. Type II fiber activation with electrical stimulation: a preliminary report. Phys Ther 1990;70:416-22.

38. Henneman E, Somjen G, Carpenter DO. Functional significance of cell size in spinal motoneurons. J Neurophysiol 1965;28:560-80.

39. Paillard T, Noe F, Bernard N, Dupui P, Hazard C. Effects of two types of neuromuscular electrical stimulation training on vertical jump performance. J Strength Cond Res 2008;22:1273-8.

40. Maffiuletti NA. Physiological and methodological considerations for the use of neuromuscular electrical stimulation. Eur J Appl Physiol 2010;110:223-34. 